DOI: https://doi.org/10.47405/mjssh.v6i7.888

\begin{tabular}{|c|c|}
\hline 4 & Malaysian Journal of Social Sciences and Humanities (MJSSH) \\
\hline $\begin{array}{l}\text { Malaysian Journa of } \\
\text { Social cciences and }\end{array}$ & Volume 6, Issue 7, July 2021 \\
\hline (MJ-sSH) & e-ISSN : 2504-8562 \\
\hline & $\begin{array}{l}\text { Journal home page: } \\
\text { www.msocialsciences.com }\end{array}$ \\
\hline
\end{tabular}

\title{
Tahap Pengetahuan Kolokasi Bahasa Arab dalam kalangan Pelajar Universiti Awam Malaysia
}

\author{
Lily Hanefarezan Asbulah' \\ ${ }^{1}$ Pusat Kajian Bahasa Arab dan Tamadun Islam, Fakulti Pengajian Islam, Universiti Kebangsaan Malaysia (UKM) \\ Correspondence: Lily Hanefarezan Asbulah (lilyhane@ukm.edu.my)
}

\begin{abstract}
Abstrak
Kolokasi merupakan aspek bahasa yang ditemui oleh semua bahasa dan merupakan gandingan dua patah perkataan (leksikal) atau lebih yang membawa maksud baru dan berbeza daripada maksud bagi perkataan tunggal (asal). Pelajar yang memiliki tahap penguasaan kolokasi yang tinggi diiktiraf sebagai individu yang mencapai tahap kompeten dalam komunikasi dan memiliki kefasihan yang tinggi. Kajian tinjauan ini bertujuan untuk mengenal pasti tahap pengetahuan kolokasi Bahasa Arab dalam kalangan pelajar university awam. Kajian ini merupakan kajian kuantittaif yang berbentuk tinjauan (crosssectional) yang melibatkan seramai 344 responden daripada kalangan pelajar tahun akhir dari lapan buah universiti awam di Malaysia. Data yang diperolehi dianalisis secara dekskriptif menggunakan perisian SPSS. Dapatan kajian menunjukkan bahawa tahap pengetahuan kolokasi Bahasa Arab dalam kalangan pelajar universiti awam adalah masih di tahap yang rendah. Situasi ini menunjukkan bahawa kelemahan ini adalah disebabkan oleh pelajar tidak dapat menguasai makna dan fungsi penggunaan sesuatu perkataan Arab itu dengan baik. Keadaan bertambah rumit apabila keterbatasan penguasaan perbendaharaan kata. Justeru, pembelajaran kolokasi perlu diberi penekanan dalam pengajaran dan pembelajaran bahasa kerana pembelajaran kolokasi bukan sahaja dapat meningkatkan pengetahuan leksikal malah dapat meningkatkan keupayaan dan kecekapan berkomunikasi samada dalam pertuturan atau penulisan. Antara cadangan yang boleh dilakukan, penggubal buku teks dapat mengambil inisiatif dengan menyediakan bahan kolokasi bagi perkataan yang berfrekuensi secara sedikit demi sedikit dari peringkat sekolah rendah dan menengah. Tidak ketinggalan, pembelajaran kolokasi berasaskan sumber data korpus juga haruslah diperkenalkan agar pelajar dapat menyerap manfaat dan potensi daripada data korpus yang menyediakan sumber bahasa Arab yang autentik.
\end{abstract}

Kata kunci: pengetahuan kolokasi, bahasa Arab, bahasa asing, universiti awam, korpus

\section{Level of Knowledge of Arabic Collocation among Malaysian Public University Students}

\begin{abstract}
Collocation is an aspect of language found in all languages and is a coupling of two or more words (lexical) that carry a new and different meaning from the meaning of a single (original) word. Students who have high level of mastery of collocation are recognized as individuals who achieve competent level in communication and possess a high level of fluency. This survey study aims to identify the level of knowledge of Arabic language collocation among public university students. This study is a quantitative study in the form of a survey (cross-sectional) involving a total of 344 respondents from final year students of eight public universities in Malaysia. The data obtained were analyzed
\end{abstract}


descriptively using SPSS software. The findings of the study show that the level of knowledge of Arabic language collocation among public university students is still at low level. This situation shows that this weakness is caused by students not being able to master the meaning and usage function of an Arabic word well. The situation is further complicated by the limitation of vocabulary mastery. Thus, collocation learning should be given emphasis in language teaching and learning because collocation learning does not only improve lexical knowledge but can also improve communication ability and efficiency either in speech or writing. Among the suggestions that can be done is that textbook writers can take the initiative by providing collocation material for frequently used words stage by stage from the primary and secondary school levels. Apart from that, collocation learning based on corpus data sources should also be introduced so that students can absorb the benefits and potential from corpus data that provide authentic Arabic language sources.

Keywords: collocation knowledge, Arab language, foreign language, public university, corpus

\section{Pengenalan}

Kolokasi merupakan aspek yang penting dalam menguasai sesuatu bahasa. Seseorang itu dikatakan memiliki pengetahuan bahasa apabila mempunyai pengetahuan kolokasi. Santilan (2010) telah menjelaskan bahawa antara kepentingan kolokasi dalam pembelajaran bahasa asing adalah ia akan meningkatkan kecekapan seseorang untuk bertutur. Hal ini kerana, antara kriteria utama yang membolehkan seseorang itu fasih terhadap sesuatu bahasa adalah kerana memiliki pengetahuan kolokasi (Nation, 2000).

Fenomena kolokasi dalam linguistik dalam kalangan ilmuan Arab sebenarnya telah mendahului para ilmuan linguistik moden hampir 1500 tahun dahulu. Antara ilmuan Arab ternama yang telah mencatat kewujudan fenomena ini adalah seperti al-Jahiz, Sibawayh, Abu Hilal Al-'Askari, Ibn Faris. Namun pada ketika itu, tiada sebarang nama atau terma telah yang disepakati antara ilmuan Arab untuk menerangkan fenomena kolokasi ini. Al-Jahiz telah menceritakan dalam kitabnya al-bayān wa altabyinn البيان و التبيين mengenai unsur leksikal di dalam al-Quran akan berganding secara berlawanan dalam keadaan positif dan negatif dalam keadaan tertentu. Antara contohnya adalah seperti مطرت أمطرت Leksikal pertama terdiri daripada kata kerja yang membawa maksud (hujan telah turun) yang menerangkan konteks mengenai Allah yang bersifat maha pemurah manakala leksikal kedua membawa maksud ia telah dihujani yang menerangkan konteks seksaan Allah. Contoh lain yang diceritakan oleh al-Jahiz dalam kitab al-quran adalah seperti والهالاة والزكاة (solat dan zakat), والجوع و الخوف (lapar dan takut), الجنة والنار (syurga dan neraka), الههاجرين والأنصار (golongan ansar dan muhajirin), الجن وال والإنس والجر (jin dan manusia) .

Walau bagaimanapun, pada pertengahan 1960-an, kajian kolokasi secara khusus telah mula dijalankan di bawah pengaruh teori Firth. Beliau mendefinisikan kolokasi sebagai kombinasi atau asosiasi antara perkataan dengan perkataan yang lain. Beliau juga terkenal dengan gelaran "father of collocation" yang telah mengasaskan pendekatan leksikal. Beliau mencetuskan suatu pembaharuan dengan mengaitkan kajian linguistik dengan aspek makna. Berbeza daripada kajian peringkat awal kemunculan ilmu Arab tradisional, kajian moden mula mencipta istilah bahasa Arab bagi menggambarkan fenomena ini. Abu Faraj merupakan antara ilmuan pertama yang memperkenalkan istilah almuṣạhabah (المصاحبة) dengan meminjam teori Firth 'meaning by collocation' (Abdul Aziz 1995).

Kemudian pada tahun 1993, Lewis memerihalkan pendekatan leksikal secara formal dalam bukunya yang bertajuk The Lexical Approach: The State of ELT and A Way Forward yang telah dijadikan pendekatan alternatif kepada pendekatan berasaskan nahu (Grammar Approach). Aspek penting yang ditekankan dalam teori ini adalah pengelompokan (chunk) dan kelancaran (fluency). Walaupun timbul kesamaran di antara garisan idiom dan kolokasi dalam kalangan para sarjana, namun Lewis telah menetapkan bahawa pengelompokan terbahagi kepada tiga kategori iaitu kolokasi (collocation), ungkapan terhad (fixed expression) dan ungkapan separa terhad (semi-fixed expressions). 
Dalam konteks Arab, terdapat juga pelbagai terminologi dan definisi juga telah diperkenalkan oleh sarjana lepas. Para sarjana Arab berbeza dalam meletakkan terminologi dan makna kolokasi dalam

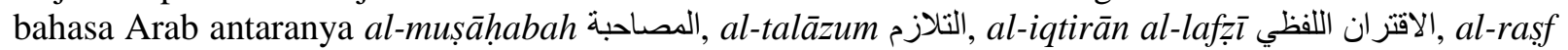

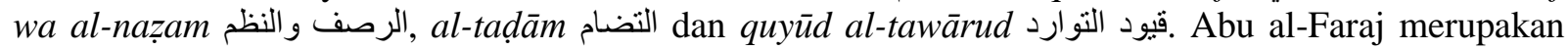
antara sarjana Arab yang terawal yang membawa teori Firth menggunakan istilah al-mușāhabah yang membawa maksud peneman bagi menerangkan konsep kolokasi dalam bahasa Arab. Beliau juga memuatkan dalam kitabnya al-macajim al-lughawiyyah fi dau'i dirasat ${ }^{c} i l m$ al-lughah wa

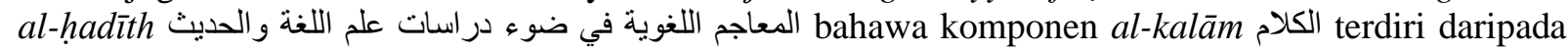

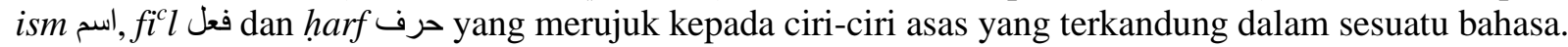
Walau bagaimanapun, terdapat satu lagi unsur yang perlu diambil kira yang digunakan dalam frasa atau al-tarkīb النحو ataupun qawä $\bar{a}^{c}$ id al-lughawiyyah dan unsur tersebut yang dinamakan sebagai kolokasi ataupun al-muṣāhhabah المصاحبة (Abu al-Faraj, 1996).

Manakala jika dirujuk dalam mucjam maqāyīs al-lughah معجم مقاييس اللغة, Ibn Faris (2001) menyatakan bahawa istilah al-muṣāhabah المصاحبة yang berasal daripada ص ح ع بائ yang membawa maksud peneman antara dua perkara. Berbeza dengan Ahmad Mukhtar Umar (1988), beliau mendefinisikan istilah kolokasi sebagai tawāfuq al-wuqū $\bar{u}^{c}$ الوقوع atau al-raşf النظم al-nazam. Begitu juga dengan Mohamad Hassan Abdul Aziz (1995) yang turut menggunakan istilah al-muṣāhabah الرعاحِ dalam kitabnya al-muṣāhabah fi al-tachörr al-lughawiyy المصاحبة في التعبير اللغوي dan memandang kolokasi sebagai fenomena yang berlaku dalam semua bahasa. Manakala Ghazala (2004) yang menggunakan istilah al-lafz̦iyyah al-mutalāzimāt اللفظية المُتنلازمَاتُ yang mendefinisikan kolokasi sebagai kombinasi leksikal yang tetap dan tidak akan berubah makna. Adapun Hafiz (2004) menggunakan istilah al-

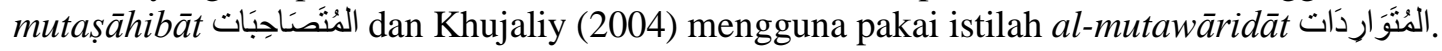

Namun begitu, Hijazi lebih cenderung menamakan kolokasi sebagai al-taḍ̂̄m التضام yang membawa maksud perkaitan sesuatu perkataan dengan perkataan yang lain yang membawa kepada struktur hubungan frasa (Hijazi, 1998). Antara ilmuan Arab yang juga menggunapakai istilah al-tadām التضام adalah Tamam Hassan bersandarkan prinsip secara nahu al-mustawa al-nahw المستوى التحو kolokasi sebagai kedudukan perkataan dalam ayat (Hassan, 1984). Manakala Abdul Fattah Abdul 'Alim Barkawi mengguna pakai istilah al-rașf الرصف dan quyūd al-tawārud قيود التوارد (Barkawi, 1991). Santilan (2010) pula memberikan pendefinisian kolokasi sebagai kombinasi kerap antara dua atau lebih leksim yang unik dan mempunyai hubungan semantik yang kuat, berbeza daripada idiom.

Walaupun para ilmuwan Arab berbeza dari sudut istilah kolokasi dalam bahasa Arab, namun mereka bersetuju dari segi kandungan makna yang dibawa. Dengan erti kata lain mereka bersetuju bahawa kolokasi merupakan turutan kata yang beriringan. Walau bagaimanapun disebabkan makna yang didukung oleh setiap perkataan adalah berbeza, maka hanya sesuatu perkataan boleh digandingkan قال : dengan perkataan yang tertentu sahaja. Contohnya kolokasi bagi kata kerja dengan satu partikel jar لهerkata kepada atau bercakap kepada. Dalam keadaan ini, tiada alasan mengapa dalam bahasa Arab $q \bar{a} l a$ lädigandingkan dengan $l i \mathrm{~J}$ yang secara harfiahnya dalam bahasa Melayu bermaksud bagi atau untuk dan bukannya qāla ila قال إلى yang membawa maksud kepada. Oleh yang demikian, apabila seseorang itu menggunakan kombinasi kolokasi yang pelik dan tidak bersesuaian dengan konteksnya, ia amat mudah untuk dikesan oleh penutur jati kerana kolokasi sering didengari dan diguna pakai dalam kehidupan mereka. Justeru, aspek kolokasi merupakan satu aspek keistimewaan bagi penutur jati bagi sesuatu bahasa tertentu di samping membantu pelajar untuk bertutur seperti penutur jati.

\section{Sorotan Literatur}

Kajian-kajian lepas juga telah menjalankan kajian yang melibatkan aspek kolokasi. Antaranya kajian yang pernah dijalankan oleh Ashinida (1998) yang berkaitan dengan al-id̄äfah dan al-na at. Instrumen yang digunakan dalam kajian ini adalah soal selidik, set ujian bertulis dan temu bual. Dapatan kajian mengupas bahawa kekeliruan timbul dalam kalangan pelajar adalah disebabkan oleh pengaruh bahasa ibunda dan minat yang kurang dalam mempelajari bahasa Arab. Di samping itu, ketiadaan teknik dan 
strategi yang berkesan bagi memahami aspek kolokasi juga mendorong pelajar mengalami masalah dalam membezakan kedua-dua aspek tersebut.

Selain itu, kajian Ab. Halim (2002) juga telah dijalankan untuk mengenal pasti keupayaan pelajar dalam frasa bahasa Arab terhadap pelajar SMU (A) YIK secara ujian bertulis. Dapatan kajian mendapati bahawa hanya $4.76 \%$ sahaja pelajar yang berjaya dalam ujian frasa kolokasi dan $95.24 \%$ pelajar yang lain dianggap gagal. Antara punca berlakunya kesilapan ini adalah disebabkan oleh kegagalan dalam memahami konsep pembentukan frasa dengan baik dan gangguan bahasa ibunda.

Seterusnya fenomena tersebut juga dibuktikan dalam kajian Ab. Halim dan Che Radiah (2007) yang telah mengkaji mengenai tahap penguasaan pelajar terhadap aspek kolokasi. Seramai 155 pelajar dari pengajian bahasa Arab di UKM, UM, UPM dan UIAM dijadikan responden dalam kajian ini. Dapatan penting kajian ini menunjukkan bahawa penguasaan para pelajar amat lemah bagi aspek kata kerja dan partikel jarr, apabila tiada seorang pun yang mencapai tahap baik dan majoriti pelajar berada di tahap yang lemah. Berbeza bagi aspek kata kerja dan kata nama, hampir 50\% pelajar berada di tahap yang baik. Antara punca utama adalah disebabkan oleh gangguan bahasa ibunda dan cubaan untuk menterjemah unsur bahasa ibunda secara harfiah dalam bahasa Melayu bagi menyampaikan mesej yang dikehendaki. Kekeliruan ini berlaku apabila perkataan bahasa Arab yang ingin diterjemahkan mempunyai satu padanan sahaja dalam bahasa Melayu.

Saifullah Kamalie (2010) juga pernah menjalankan kajian mengenai aspek kolokasi namun tumpuan bidang adalah berfokus kepada penterjemahan dalam kitab Fi Zilal al-Quran bagi jenis kolokasi binaan ma + min, frasa sendi, kata nama + frasa sendi, partikel amma + fa. Sungguhpun begitu, dapatan kajian beliau menggariskan bahawa muncul terjemahan secara harfiah rentetan daripada ketiadaan pengetahuan penterjemah mengenai kolokasi serta penggunaannya yang sebenar, lebih-lebih lagi bagi kolokasi yang berbentuk idiom, ungkapan tetap dan peribahasa.

Selain itu, kajian Uraidah ( 2014) terhadap 60 orang pelajar tingkatan empat aliran sains agama di Sekolah Menengah Kebangsaan Seksyen 18 Shah Alam secara kuasi eksperimen mendapati bahawa penguasaan pelajar terhadap penguasaan kolokasi $\mathrm{KN}+\mathrm{KN}$ (al-idāfah) adalah di tahap rendah. Walaupun penyusunan grafik membantu para pelajar untuk menentukan gandingan kolokasi $\mathrm{KN}+\mathrm{KN}$ (al-id̄a $f a h)$ dan $\mathrm{KN}+\mathrm{KA}\left(a l-n a^{c} a t\right)$ yang betul, namun ia tidak dapat meningkatkan kemahiran membina ayat. Hal ini kerana, penguasaan pelajar bagi kedua-dua kategori dari segi membina ayat masih di tahap sederhana.

Kesimpulan daripada tinjauan kajian lepas bagi konteks di Malaysia, pengkaji mendapati bahawa para pelajar mempunyai masalah dalam menguasai kolokasi bahasa Arab disebabkan oleh faktor gangguan bahasa ibunda, gagal memahami konsep kolokasi dengan baik dan ketiadaan strategi dan teknik yang berkesan. Walaupun penyelidik lepas telah menyatakan beberapa langkah yang perlu diambil, namun masih terdapat kelompangan yang wujud kerana terdapat isu di mana proses kesahan dan format yang standard tidak diperincikan . Perkataan yang dipilih dalam ujian kolokasi ini juga tidak disaring berdasarkan pendedahan penggunaannya di peringkat universiti terutamanya di peringkat ijazah.

Justeru, pemurnian dan pembaharuan relevan dilakukan kerana antara perkara yang perlu dititikberatkan dalam mengukur sesuatu pengetahuan aspek bahasa pelajar adalah pemilihan format ujian yang melalui proses kesahan, penekanan kriteria item pengganggu (distractor) dan kriteria pemilihan perkataan yang akan diuji (Nguyen \& Webb 2016). Ini penting untuk mengenal pasti pola kolokasi bahasa Arab yang benar-benar tidak jelas yang membelenggu para pelajar (El-Dakhs, 2015) dan seterusnya mengenal pasti tahap penguasaan kolokasi Bahasa Arab dalam kalangan pelajar di peringkat universiti awam.

\section{Metod Kajian}

Kajian ini merupakan kajian berbentuk kajian kuantitatif yang menggunakan kaedah tinjauan (crosssectional) untuk mentadbir tinjauan terhadap sampel dan keseluruhan populasi untuk menerangkan 
sikap, pendapat, kelakuan dan ciri-ciri subjek populasi (Creswell, 2012). Populasi kajian ini pula terdiri daripada pelajar pengajian sarjana muda bahasa Arab daripada universiti-universiti awam yang mempunyai jabatan bahasa Arab dan menawarkan pengajian ijazah sarjana muda bahasa Arab di seluruh Malaysia iaitu Universiti Kebangsaan Malaysia, Universiti Putra Malaysia, Universiti Malaya, Universiti Islam Antarabangsa Malaysia, Universiti Sains Islam Malaysia, Universiti Pendidikan Sultan Idris dan Universiti Sultan Zainal Abidin. Para pelajar juga merupakan bakal pelajar ijazah sarjana muda bahasa Arab yang terdiri daripada pelajar tahun akhir pengajian yang telah melalui tahun pengajian pertama, kedua dan ketiga. Pemilihan populasi kajian terhadap pelajar tahun akhir di universiti awam adalah terhadap pelajar di akhir pengajian sahaja. Pemilihan ini dibuat berdasarkan faktor kematangan dan pengalaman mereka dalam mempelajari bahasa Arab di peringkat universiti secara khususnya.

Kaedah pensampelan yang digunakan dalam kajian ini menggunakan kaedah pensampelan rawak mudah. Kaedah ini dipilih berdasarkan kemampuan pengkaji untuk mendapatkan kerangka pensampelan (sampling frame).Penggunaan kaedah ini sesuai digunakan kepada populasi yang bersifat seragam (homogenous) seperti universiti-universiti awam di Malaysia yang menawarkan kos pengajian bahasa Arab. Manakala data kajian ini dianalisis secara deskriptif menggunakan SPSS.

\section{Ujian Pengetahuan Kolokasi Bahasa Arab}

Dalam kajian ini, instrumen set ujian kolokasi telah digunakan. Set ujian kolokasi telah diadaptasi daripada ujian Receptive Collocation Test berdasarkan kajian Younghui et al. (2015). Ujian ini telah menggunakan aneka pilihan jawapan dan menambah satu lagi item pengganggu (distractor) iaitu 'saya tidak tahu' ( أنا لا أعرف). Hal ini kerana, bagi mengelakkan para pelajar meneka secara terus daripada pilihan jawapan yang disediakan. Tujuan ujian ini dijalankan adalah untuk melihat sejauh mana penguasaan pelajar terhadap pengetahuan kolokasi bahasa Arab berdasarkan tahap frekuensi kekerapan 1000,2000,3000 dan 4000 yang paling kerap dalam bahasa Arab. Oleh itu, sebanyak 40 item telah dibangunkan melalui ujian ini.

Pengkaji juga mengambil sampel perkataan untuk digunakan dalam ujian kolokasi bahasa Arab daripada kamus terbaru dan terkini oleh Tim Buckwalter dan Dilworth Parkinson yang bertajuk $A$ Frequency Dictionary of Arabic Core Vocabulary For Learners. Kamus ini mempamerkan 4000-5000 entri perkataan yang digunakan dalam penggunaan bahasa Arab Standard dan dialek. Selain itu, kamus ini juga merujuk kepada data korpus Arab yang mempunyai 30 juta patah perkataan secara lisan dan bertulis dari pelbagai negara (Buckwalter \& Parkinson, 2014).

Pengkaji berpendapat penggunaan kamus ini dilihat sangat relevan dengan masa kini kerana kamus ini mempromosikan penggunaan frekuensi yang menggambarkan populariti sesuatu perkataan itu secara langsung (Zainur, 2013) bersesuaian dengan objektif kajian ini yang digariskan iaitu untuk melihat tahap pengetahuan kolokasi bahasa Arab pelajar berdasarkan tahap frekuensi 1000,2000,3000 dan 4000 perkataan paling kerap dalam bahasa Arab. Webb dan Sasao (2013) berpandangan bahawa pengukuran berdasarkan tahap frekuensi yang berbeza akan menjadikan sesuatu kajian tersebut mempunyai nilai mutu yang tinggi. Walaupun frekuensi perkataan yang dipamerkan ini berdasarkan kekerapan perkataan tunggal dan bukan frasa kolokasi, isu ini tidak menimbulkan masalah kepada pengkaji. Hal ini kerana, Nguyen dan Webb (2016) juga membuat kesimpulan daripada dapatan kajian beliau bahawa pengukuran pengetahuan kolokasi perlu diukur berdasarkan kekerapan perkataan tunggal dan bukan kekerapan padanan kolokasi tersebut.

Perkataan-perkataan ini disaring berdasarkan kesesuaian dan penggunaannya dalam konteks pembelajaran bahasa Arab di Malaysia. Pengkaji telah merujuk kamus Asia Tenggara yang telah dibangunkan oleh Abdul Rahman yang mempunyai perkataan-perkataan yang disaring berdasarkan enam parameter iaitu al-syuyu' الثيوع(frekuensi), al-tauzī التوزيع (keluasan penggunaan), qābaliyyah

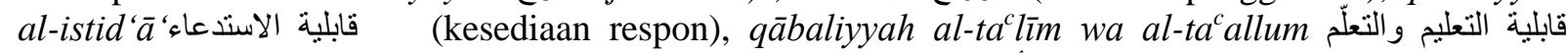
(keupayaan pengajaran dan pembelajaran) dan al-ahammiyyah الأهمية (kepentinganya). 
Berdasarkan kekerapan perkataan tertinggi tersebut, untuk melihat padanan kolokasi yang bersesuaian, pengkaji telah merujuk kekerapannya yang tertinggi pada korpus Arab berdasarkan aplikasi konkordans al-munaqab al-'Arabiyy المنقب العربي yang telah dibangukan oleh Universiti Islam Antarabangsa. Bagi memastikan padanan tersebut adalah bertepatan dan relevan, kamus al-mucjam al-

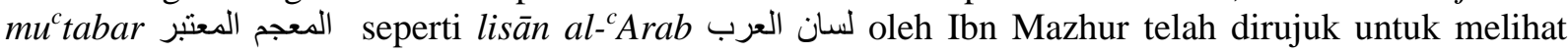
ketepatan konteksnya penggunaannya. Kamus ini dipilih kerana merupakan antara kamus yang lengkap dan menjadi rujukan utama dalam dunia bahasa Arab.

Rajah 1: Langkah pemilihan sampel kolokasi yang di uji

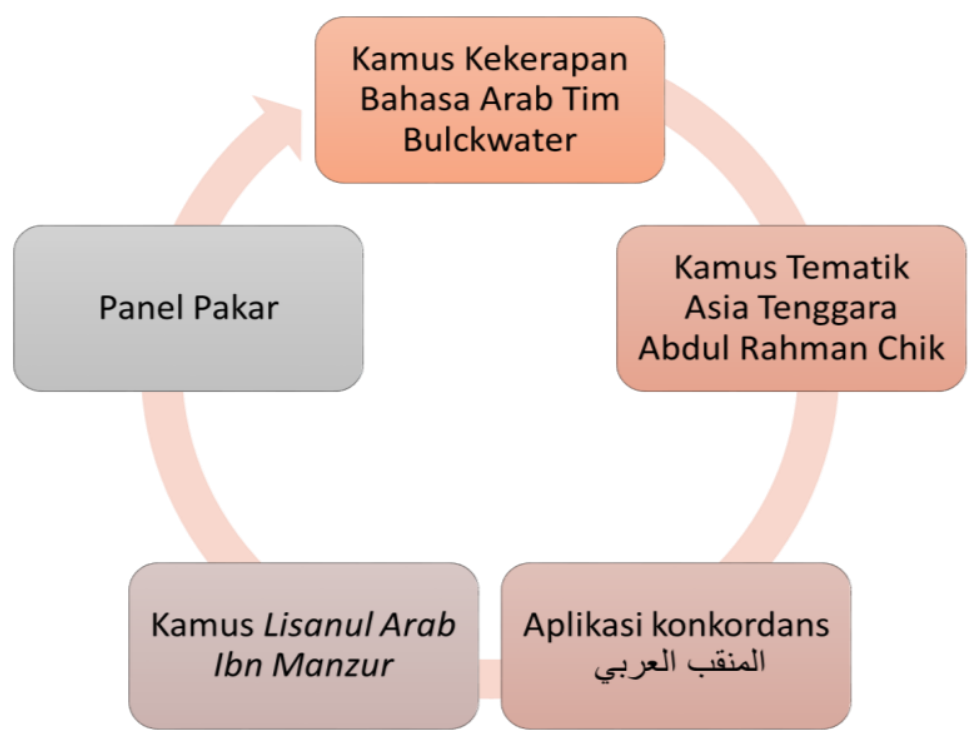

\section{Kesahan dan Kebolehpercayaan Instrumen Kajian}

Kesahan merupakan konsep yang penting dalam konteks pengukuran sesuatu konstruk. Kesahan sesuatu pengukuran itu bergantung kepada sejauh mana ia berjaya mengukur apa yang hendak diukur (Azizi Yahya et al., 2017). Oleh itu, instrumen tersebut perlu melalui proses kesahan muka (face validity) dan kesahan kandungan (contain validity) bagi menyemak aspek bahasa, struktur dan susunan ayat yang sesuai ataupun tidak dengan komponen dalam pengukuran dan maksud item yang ditanya (Mohd. Najib, 2003).

Oleh yang demikian, seramai empat orang pakar telah dilantik menjadi panel pakar untuk memastikan pemilihan item kolokasi yang terkandung dalam ujian bersesuaian mengikut aras kesukaran kolokasi yang diuji. Mereka mempunyai kepakaran dalam leksikografi bahasa Arab, penilaian bahasa (language testing) dan psikometrik dan merupakan pensyarah daripada Fakulti Ilmu Wahyu dan Sains Kemanusiaan (UIAM), Fakulti Pengajian Bahasa Utama (USIM), Fakulti Pendidikan (UIAM) dan Fakulti Pengajian Islam (UKM). Bagi memastikan instrumen ujian tersebut tiada kesalahan bahasa, ujian tersebut telah dihantar kepada proses proofreading untuk semakan ketepatan bahasa sebelum instrumen diedarkan kepada responden. Fokus perbincangan memberi tumpuan kepada pemilihan frasa kolokasi yang diuji, konteks ungkapan ayat serta gaya bahasa dalam ujian reseptif kolokasi bahasa Arab.

Seterusnya untuk membolehkan kebolehpercayaan antara pakar dicapai, pengkaji telah menggunakan Indeks Kesahan Kandungan (Content Validation Index-CVI). Menurut Lynn (1986), julat nilai purata tahap persetujuan antara pakar yang diterima adalah melebihi nilai 0.80 . Secara keseluruhan, kesemua nilai mencapai pekali persetujuan menunjukkan nilai persetujuan yang munasabah iaitu melebihi nilai 0.80. Nilai ini bermaksud bahawa kesemua item dalam instrumen ujian mencapai pekali persetujuan yang baik dalam kalangan panel pakar. Seterusnya, panel pakar juga memperakui bahawa instrumen mampu mengukur aspek kandungan yang hendak diukur namun terdapat beberapa ungkapan ayat yang perlu dilihat semula penggunaannya kerana seolah-olah tergantung dari segi maknanya. Dikhuatiri mengelirukan responden. 


\section{Hasil Kajian}

Kutipan data dalam kajian ini meliputi lapan buah universiti awam yang menawarkan program Ijazah Sarjana Muda Bahasa Arab. Merujuk Jadual 1, responden terdiri daripada pelajar tahun akhir sepenuh masa yang sedia ada di 8 buah universiti awam yang menawarkan program Ijazah Sarjana Muda Bahasa Arab. Seramai 344 pelajar telah mengambil bahagian dalam soal selidik dan ujian ini. Perbincangan dapatan kajian akan dibentangkan berkaitan demografi responden.

Jadual 1: Maklumat Demografi responden

\begin{tabular}{|c|c|c|c|}
\hline \multicolumn{2}{|l|}{ Demografi Responden } & \multirow{2}{*}{$\begin{array}{l}\text { Frekuensi } \\
84\end{array}$} & \multirow{2}{*}{$\begin{array}{l}\text { Peratus } \\
24.4\end{array}$} \\
\hline Jantina & Lelaki & & \\
\hline & Perempuan & 260 & 75.6 \\
\hline \multirow[t]{10}{*}{ Universiti } & Universiti Sains Islam Malaysia & 90 & 26.2 \\
\hline & (USIM) & 49 & 14.2 \\
\hline & Universiti Islam Antarabangsa (UIAM) & 47 & 13.7 \\
\hline & Universiti Putra Malaysia (UPM) & 20 & 5.8 \\
\hline & Universiti Malaya (UM) & 49 & 14.2 \\
\hline & Universiti Kebangsaan Malaysia & 16 & 4.7 \\
\hline & $(\mathrm{UKM})$ & 55 & 16.0 \\
\hline & Universiti Teknologi MARA (UiTM) & 18 & 5.2 \\
\hline & $\begin{array}{l}\text { Universiti Pendidikan Sultan Idris } \\
\text { (UPSI) }\end{array}$ & & \\
\hline & $\begin{array}{l}\text { Universiti Sultan Zainal Abidin } \\
\text { (UniSZA) }\end{array}$ & & \\
\hline \multicolumn{4}{|c|}{$\begin{array}{l}\text { Jumlah Jam Peruntukan Belajar Bahasa Arab dalam } \\
\text { Seminggu }\end{array}$} \\
\hline Membaca buku bahasa & 0-1 Jam & 189 & 54.9 \\
\hline Arab & 1-2 Jam & 111 & 32.3 \\
\hline & Lebih 2 Jam & 44 & 12.8 \\
\hline \multirow{3}{*}{$\begin{array}{l}\text { Melayari laman web } \\
\text { bahasa Arab }\end{array}$} & 0-1 Jam & 170 & 49.4 \\
\hline & 1-2 Jam & 132 & 38.4 \\
\hline & Lebih 2 Jam & 42 & 12.2 \\
\hline \multirow{3}{*}{$\begin{array}{l}\text { Menggunakan bahasa } \\
\text { Arab untuk berhubung } \\
\text { (facebook, email, sms, } \\
\text { whatsapp dan telegram) }\end{array}$} & 0-1 Jam & 223 & 64.8 \\
\hline & 1-2 Jam & 93 & 27.0 \\
\hline & Lebih 2 Jam & 28 & 8.1 \\
\hline \multirow{3}{*}{$\begin{array}{l}\text { Berinteraksi dengan } \\
\text { rakan dan pensyarah } \\
\text { dalam bahasa Arab }\end{array}$} & 0-1 Jam & 193 & 56.1 \\
\hline & 1-2 Jam & 114 & 33.1 \\
\hline & Lebih 2 Jam & 37 & 10.8 \\
\hline \multirow{3}{*}{$\begin{array}{l}\text { Melibatkan diri dalam } \\
\text { aktiviti bahasa Arab } \\
\text { anjuran persatuan } \\
\text { bahasa Arab }\end{array}$} & 0-1 Jam & 138 & 40.1 \\
\hline & 1-2 Jam & 125 & 36.3 \\
\hline & Lebih 2 Jam & 81 & 23.5 \\
\hline \multirow{3}{*}{$\begin{array}{l}\text { Menonton tv, filem atau } \\
\text { video bahasa Arab }\end{array}$} & 0-1 Jam & 191 & 55.5 \\
\hline & 1-2 Jam & 121 & 35.2 \\
\hline & Lebih 2 Jam & 32 & 9.3 \\
\hline \multirow{3}{*}{$\begin{array}{l}\text { Mendengar siaran radio } \\
\text { bahasa Arab }\end{array}$} & 0-1 Jam & 268 & 77.9 \\
\hline & 1-2 Jam & 66 & 19.2 \\
\hline & Lebih 2 Jam & 10 & 2.9 \\
\hline \multicolumn{4}{|c|}{ Tahap Penguasaan Bahasa Arab } \\
\hline Kemahiran Bertutur & 1- Amat Lemah & 16 & 4.7 \\
\hline
\end{tabular}



DOI: https://doi.org/10.47405/mjssh.v6i7.888

\begin{tabular}{llll}
\hline & 2- Lemah & 64 & 18.6 \\
& 3-Sederhana & 199 & 57.8 \\
& 4-Baik & 63 & 18.3 \\
5-Amat Baik & 2 & 6 \\
Kemahiran Menulis & 1- Amat Lemah & 8 & 2.3 \\
& 2- Lemah & 32 & 9.3 \\
& 3-Sederhana & 184 & 53.5 \\
& 4-Baik & 108 & 31.4 \\
& 5-Amat Baik & 12 & 3.5 \\
Kemahiran Membaca & 1- Amat Lemah & 5 & 1.5 \\
& 2- Lemah & 21 & 6.1 \\
& 3-Sederhana & 151 & 43.9 \\
& 4-Baik & 136 & 39.5 \\
& 5-Amat Baik & 31 & 9.0 \\
Kemahiran Mendengar & 1- Amat Lemah & 6 & 1.7 \\
& 2- Lemah & 25 & 7.3 \\
& 3-Sederhana & 167 & 48.5 \\
& 4-Baik & 128 & 37.2 \\
Bidang Ingin Diceburi & 18 & 5.2 \\
5elepas Tamat & 1- Pendidikan & 189 & 54.9 \\
& 2-Penterjemahan & 34 & 9.9 \\
& 3-Kewartawanan & 35 & 10.2 \\
& 4-Pengurusan & 46 & 13.4 \\
& 5-Penyiaran atau Media & 10 & 2.9 \\
& 6-Penerbitan & 18 & 5.2 \\
& 7-Perlancongan & 4 & 1.2 \\
8-Perniagaan & 8 & 2.3 \\
\hline
\end{tabular}

Majoriti responden adalah daripada Universiti Sains Islam Malaysia iaitu seramai 90 orang pelajar (26.2\%), diikuti dengan responden daripada Universiti Pendidikan Sultan Idris iaitu seramai 55 orang pelajar (16\%). Manakala universiti yang mempunyai bilangan responden yang sama iaitu Universiti Islam Antarabangsa dan Universiti Kebangsaan Malaysia iaitu seramai 49 orang (14.2\%) diikuti dengan Universiti Putra Malaysia iaitu seramai 47 orang (13.7\%). Seterusnya adalah Universiti Malaya dan Universiti Sultan Zainal Abidin masing-masing dengan jumlah seramai 20 orang pelajar (5.8\%) dan 18 orang (5.2\%). Manakala responden yang mempunyai paling minima penyertaan adalah daripada Universiti Teknologi MARA dengan jumlah 16 orang pelajar (4.7\%).

Dapatan juga menunjukkan bahawa lima aktiviti teratas yang digemari oleh para pelajar dengan peruntukan masa yang lebih 2 jam adalah, melibatkan diri dalam anjuran persatuan, membaca buku bahasa Arab, melayari laman web bahasa Arab, berinteraksi dengan rakan dan pensyarah dan menonton tv, video dan filem. Walau bagaimanapun, kebanyakan responden memperuntukkan masa dengan aktiviti bahasa Arab adalah antara 0-1 jam dalam seminggu.

Dari aspek tahap penguasaan bahasa Arab dalam kemahiran membaca,seramai 151 orang pelajar (43.9\%) menyatakan tahap penguasaan adalah sederhana, 136 orang $(39.5 \%)$ menyatakan tahap penguasaan adalah baik, diikuti dengan tahap penguasaan amat baik, lemah dan amat lemah iaitu seramai 31 orang (9\%), 21 orang (6.15) dan 5 orang (1.5\%) masing-masing. Manakala bagi aspek kemahiran mendengar, seramai 167 orang pelajar (48.5\%) berada pada tahap sederhana diikuti seramai 128 orang pelajar (37.2\%) pada tahap baik. Peratusan ini menunjukkan bahawa majoriti responden mempunyai kemampuan yang sederhana pada aspek reseptif iaitu bagi kemahiran membaca dan mendengar dalam mempelajari bahasa Arab.

Manakala dari segi bidang kerjaya yang ingin diceburi selepas tamat pengajian, dapatan menunjukkan seramai 189 orang yakni lebih daripada 50\% bakal pelajar berminat untuk menjadi pendidik. Manakala 
seramai 46 orang berminat untuk menceburi bidang pengurusan diikuti dengan bidang kewartawanan dan penterjemahan iaitu seramai 35 orang (10.2\%) dan 34 orang pelajar (9.9\%). Seterusnya, seramai 18 orang berminat dalam bidang penerbitan diikuti 10 orang pelajar dalam bidang penyiaran atau media. Bidang yang kurang mendapat tempat di kalangan responden adalah perniagaan dan pelancongan, dengan masing-masing menyatakan minat dengan jumlah sebanyak 8 orang $(2.3 \%)$ dan 4 orang pelajar $(1.2 \%)$ sahaja. Hal ini menunjukkan bahawa kebanyakan responden berminat untuk menceburi kerjaya dalam bidang pendidikan sama ada pensyarah di universiti ataupun sebagai guru di sekolah-sekolah.

Secara keseluruhan demografi responden, para pelajar mempunyai faktor kemampuan dan penguasaan yang sederhana dalam pembelajaran bahasa Arab. Ini bertepatan apabila rata-rata para pelajar memperuntukkan masa terhadap aktiviti bahasa Arab yang agak terbatas dalam lingkungan 0-1 jam sahaja dalam seminggu. Namun begitu, pelajar mempunyai kelebihan dari aspek kesediaan untuk menceburi laluan dalam bidang pendidikan sekali gus menunjukkan bahawa minat dan kemampuan para pelajar dalam bahasa Arab boleh digilap lagi untuk peringkat pembelajaran yang seterusnya iaitu di peringkat sarjana dan doktor falsafah bagi melahirkan para pendidik yang cemerlang.

\section{Tahap Pengetahuan Kolokasi Bahasa Arab}

Kajian ini telah menggunakan analisis statistik deskriptif ataupun disebut sebagai statistik keperihalan bagi menghuraikan ciri-ciri sesuatu pemboleh ubah dengan menggunakan petunjuk min, sisihan piawai, frekuensi, peratusan dan seterusnya membuat kesimpulan berdasarkan data numerikal (Ghazali Darusalam \& Sufean Hussin, 2016). Bagi data yang diperoleh daripada soal selidik, kajian ini telah menggunakan nilai interpretasi tahap skor min yang digariskan oleh Oxford (1990) iaitu 1.0 hingga 2.4 membawa tafsiran tahap rendah, manakala skor min antara 2.5 hingga 3.4 berada di tahap sederhana dan 3.5 hingga 5.0 berada pada tahap yang tinggi.

Berdasarkan Jadual 2, kajian ini mendapati bahawa skor pencapaian pengetahuan kolokasi bahasa Arab antara 0-1000 perkataan adalah seramai 222 orang (64.5\%), skor pencapaian antara 1100-2000 perkataan adalah seramai 70 orang (20.3\%), skor pencapaian 2100-3000 adalah seramai 50 orang (14.5\%). Sementara itu. Hanya 2 orang pelajar (0.6\%) memperoleh skor pencapaian antara 3100-4000. Nilai skor min keseluruhan bagi pengetahuan kolokasi adalah 24.7 manakala sisihan piawai adalah 5.39. Keadaan ini menunjukkan bahawa majoriti pelajar berada pada interpretasi yang rendah dalam pengetahuan aspek kolokasi bahasa Arab.

Jadual 2: Pengetahuan kolokasi berdasarkan ujian kolokasi Bahasa Arab

\begin{tabular}{lll}
\hline Pengetahuan Kolokasi & Kekerapan & Peratusan \\
\hline $0-1000$ & 222 & 64.5 \\
$1100-2000$ & 70 & 20.3 \\
$2100-3000$ & 50 & 14.5 \\
$3100-4000$ & 2 & 0.6 \\
\hline Jumlah & 344 & 100 \\
\hline
\end{tabular}

\section{Perbincangan Kajian}

Tahap pengetahuan kolokasi bahasa Arab dalam kalangan pelajar di peringkat IPT masih lagi berada di tahap yang rendah. Dapatan kajian ini selari dengan kajian kolokasi dalam kalangan pelajar Melayu yang pernah dijalankan oleh (Ab. Halim, 2002; Ab. Halim \& Che Radiah, 2007; Ashinida, 1998) yang mendapati bahawa tahap penguasaan kolokasi masih rendah dan tidak memberangsangkan.

Fenomena kelemahan yang timbul ini juga sering berlaku dalam konteks bahasa kedua atau bahasa asing yang melaporkan hasil yang hampir sama (Fathy, 2007; Nesselhauf, 2003; Nguyen \& Webb, 2016; Shehata, 2008; Shei \& Pain, 2000). Keadaan ini menunjukkan bahawa kelemahan ini perlu ditangani dan perlu diberi perhatian serius dalam proses pembelajaran bahasa terutamanya dalam pembelajaran bahasa Arab sebagai bahasa asing di Malaysia. 
Kesilapan pelajar terhadap pengetahuan kolokasi bahasa Arab dapat dikenal pasti melalui padanan kolokasi yang dipilih. Antara isu yang timbul apabila pelajar keliru dalam memilih gandingan kolokasi yang tepat bagi $\mathrm{KK}+\mathrm{KS}$, contohnya pelajar cenderung memilih احتقل

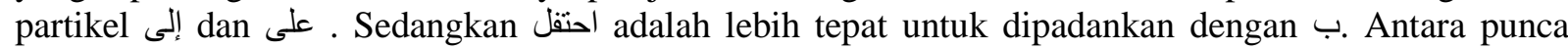
berlakunya pemilihan kata partikel yang salah adalah disebabkan oleh kecenderungan pelajar untuk menterjemah perkataan bahasa Melayu ke dalam bahasa Arab secara literal di samping kepelbagaian jenis kata partikel dalam bahasa Arab yang mewakili makna tersendiri telah menimbulkan kekeliruan dalam kalangan pelajar. Keadaan yang sama berlaku dalam dapatan kajian Ab. Halim Muhammad \& Che Radiah Mezah (2007) apabila para pelajar kerap menggandingkan يعتمد bersama dengan إلى dan bukannya dengan على Hal ini kerana pelajar gemar untuk menterjemah perkataan بعتى إلى untuk menjadikan terjemahan dalam bahasa Melayu bergantung kepada walaupun gandingan yang tepat dalam konteks bahasa Arab adalah يعتمد على.

Begitu juga dengan kesilapan yang berlaku bagi KN+KN, apabila pelajar memilih لعبة قومية yang sepatutnya لعبة شعبية dalam konteks bahasa Arab menunjukkan maksud permainan rakyat atau permainan tradisional. Kesilapan ini adalah disebabkan oleh keterbatasan perbendaharaan kata yang dikuasai oleh pelajar yang menyebabkan mereka memilih perkataan yang hampir sama maksud bagi menentukan kolokasi yang tepat. Dapatan ini dilihat selari dengan responden kajian Uraidah Abdul Wahab (2014) yang terdiri daripada pelajar sekolah menengah apabila pelajar cenderung memilih

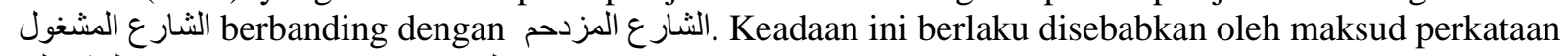
المزدحم menyamai makna membawa makna sibuk atau sesak.

Tegasnya, dapatan ini menunjukkan bahawa kelemahan pelajar dalam aspek kolokasi bahasa Arab masih lagi berterusan. Situasi ini menunjukkan bahawa kelemahan ini adalah disebabkan oleh pelajar tidak dapat menguasai makna dan fungsi penggunaan sesuatu perkataan Arab itu dengan baik. Keadaan bertambah rumit apabila keterbatasan penguasaan perbendaharaan kata (Uraidah, 2014). Justeru, pembelajaran kolokasi perlu diberi penekanan dalam pengajaran dan pembelajaran bahasa kerana pembelajaran kolokasi bukan sahaja dapat meningkatkan pengetahuan leksikal malah dapat meningkatkan keupayaan dan kecekapan berkomunikasi sama ada dalam pertuturan atau penulisan (Lewis, 2000).

\section{Kesimpulan}

Hasil kajian ini membuktikan bahawa tahap pengetahuan kolokasi bahasa Arab masih rendah dan kurang memberangsangkan. Kajian ini mencadangkan agar dapatan kajian ini dijangka dapat dimanfaatkan oleh pihak yang bertanggungjawab seperti penggubal dasar dan institusi pendidikan guru, universiti dan sekolah dengan mengemaskinikan kurikulum mata pelajaran bahasa Arab terutama dari segi aspek kosa kata agar dapat menerapkan maklumat dan aktiviti yang berbentuk strategi pembelajaran kolokasi. Selain itu, bahagian buku teks atau penggubal buku teks juga perlu mengambil inisiatif dengan menyediakan buku teks yang memperkenalkan kolokasi bagi perkataan yang berfrekuensi secara sedikit demi sedikit dari peringkat sekolah rendah dan menengah. Tidak ketinggalan, pembelajaran kolokasi berasaskan sumber data korpus juga haruslah diperkenalkan agar pelajar dapat menyerap manfaat dan potensi daripada data korpus yang menyediakan sumber bahasa Arab yang autentik.

Memandangkan kajian ini mempunyai beberapa limitasi kajian, maka cadangan kajian lanjutan digariskan untuk diselidiki dan diinovasi oleh pengkaji akan datang agar diperluaskan kepada skop institusi pengajian swasta di Malaysia atau pun perbandingan dengan negara lain. Responden kajian ini juga terdiri daripada pelajar ijazah sarjana muda sahaja. Oleh itu, skop kajian boleh diperluaskan kepada peringkat diploma, sarjana dan doktor falsafah bagi menggambarkan pengetahuan aspek kolokasi secara menyeluruh. Selain itu, kajian ini juga merupakan kajian tinjauan (cross-sectional) yang menggunakan ujian pengetahuan aspek kolokasi secara reseptif. Dicadangkan agar kajian akan datang akan mengukur dari aspek penguasaan kolokasi melalui aspek produktif menggunakan kajian secara longitudinal dan kualitatif agar dapatan lebih mendalam dan berupaya memahami isu ini dengan lebih baik. 


\section{Rujukan}

Ab. Halim Mohamad. (2002). Pembelajaran Frasa Bahasa Arab di Kalangan Pelajar Melayu: Satu Analisis Kesalahan. University Malaya.

Ab. Halim Muhammad, \& Che Radiah Mezah. (2007). Kolokasi: Aspek Penting Dalam Pengusaan Bahasa Arab: Satu Kajian di Kalangan Pelajar IPTA. Persidanagan Pengajaran Dan Pembelajaran Di Peringkat Pengajian Tinggi CTLHE07, 139-148.

Abu al-Faraj, M. A. (1996). Ma'ajim al-Lughawiyyat fi Daw'i Dirasat 'ilm al-Lughat al-Hadith. Dar al-Nahdah al-'Arabiyyat.

Ahmad Mukhtar Umar. (1988). Ilmu Ad-Dilalah. Beirut: Aalam Al-Kutub.

Ashinida Aladdin. (1998). Kekeliruan antara al-idafat dan al-na'at di kalangan pelajar Melayu. Universiti Malaya.

Azizi Yahya, Peter Voo, Ismail Maakip, \& Mohd Dahlan A. Malek. (2017). Kaedah Penyelidikan Dalam Pendidikan. Universiti Pendidikan Sultan Idris.

Barkawi, A. F. A. A. (1991). Dilalah Siyaq baina Turath wa 'Ilm Lughah wal Hadith. Kaherah: DarManar.

Buckwalter, T., \& Parkinson, D. (2014). A Frequency Dictionary of Arabic Core Vocabulary for Learners. https://doi.org/10.4324/9780203937631

Choi, Y., V.Chon, Y., \& Han, M.-S. (2015). L2 learners ' knowledge of verb-noun collocations : congruency, L2 proficiency and learning strategies. Korean Journal of Applied Linguistics, 31(3), 31-63.

Creswell, J. W. (2012). Educational Research Planning, Conducating and Evaluating Quantitative and Qualitative Research. Pearson.

El-Dakhs, D. A. S. (2015). The Lexical Collocational Competence of Arab Undergraduate EFL Learners. International Journal of English Linguistics, 5(5), 60-74. https://doi.org/10.5539/ijel.v5n5p60

Fathy, S. Y. (2007). Student' s Problems in Translating Collocations from Arabic into English. Adab Al-Rafidayn, 45, 27-48.

Ghazala, H. (2004). Essays in Translation and Stylistics. Beirut: Dar al-Ilm Lilamalayin.

Ghazali Darusalam, \& Sufean Hussin. (2016). Metodologi Penyelidikan dalam Pendidikan. Penerbit Universiti Malaya.

Hafiz, A.-T. (2004). Al-Hafiz Arabic Collocation Dictionary.

Hassan, T. (1984). al-Lughatul Arabiah Ma'naha wa Mabnaha. Kaherah : Dar al-Fikr al-Arabi.

Hijazi, M. F. (1998). Madkhal ila 'Ilm Lughah. Kaherah: Dar- Quba'.

Khujaliy, H. (2004). al-Mutarjim wa al-Mutawaridat.

Lewis, M. (2000). Teaching Collocation Futher Developements in the Lexical Approach. Heinle Cengage Learning.

Mohamad Hassan Abdul Aziz. (1995). al-Musahabah fi Ta'bir Lughawi. al-Kaherah : Dar Fikr alArabi.

Mohd. Najib Abdul Ghafar. (2003). Reka Bentuk Tinjauan Soal Selidik Pendidikan. Universiti Teknologi Malaysia Skudai.

Nation, I. S. P. (2000). Learning Vocabulary in Another Language. In Cambridge Applied Linguistics. https://doi.org/10.1017/CBO9781107415324.004

Nesselhauf, N. (2003). The Use of Collocations by Advanced Learners of English and Some Implications for Teaching. Applied Linguistics, 24(2), 223-242+268. https://doi.org/10.1093/applin/24.2.223

Nguyen, T. M. H., \& Webb, S. (2016). Examining second language receptive knowledge of collocation and factors that affect learning. Language Teaching Research, 1-23. https://doi.org/10.1177/1362168816639619

Oxford, R. L. (1990). Language learning strategies: What every teacher should know. Newbury House Publisher.

Saifullah Kamalie. (1997). Masalah penterjemahan kolokasi bahasa Arab ke bahasa Melayu: satu kajian teks tafsir. Universiti Malaya.

Santilan Grimm, P. (2010). Teaching collocation in the Arabic as a foreign language class. Enseñanza Y Aprendizaje de La Lengua Arabe, 163.

Shehata, A. K. (2008). Influence on the Reception and Production of Collocations by Advanced 
DOI: https://doi.org/10.47405/mjssh.v6i7.888

EsL/EFL Arabic Learners of English (Issue August). Ohio University.

Shei, C. C., \& Pain, H. (2000). An ESL writer's collocational aid. Journal of Computer Assisted Language Learning, 13(2), 167-182.

Uraidah Abdul Wahab. (2014). Penggunaan Penyusun Grafik Dalam Penguasaan Kolokasi Bahasa Arab. Universiti Malaya.

Webb, S. A., \& Sasao, Y. (2013). New directions in vocabulary testing. RELC Journal, 44(3), 263277. https://doi.org/10.1177/0033688213500582

Zainur Rijal Abdul Razak. (2013). Media Akhbar dan Penggunaan Bahasa Arab Standard Moden. Jurnal Komunikasi, 29(2), 107-124. 